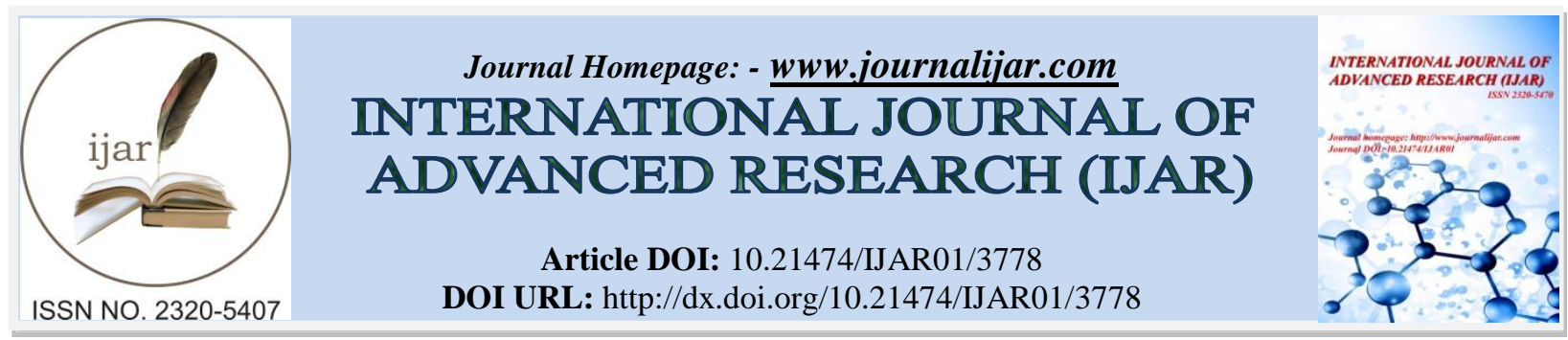

RESEARCH ARTICLE

\title{
IMPACT OF 360-DEGREE FEEDBACK ON EMPLOYEE AND ORGANIZATION GROWTH: WITH REFERENCE TO HIGHER EDUCATION INSTITUTES OF PAKISTAN.
}

Prof. Dr. Saima Tabassum Siddiqui, Ph.D, MS, MBA.

Assistant Professor (Business Administration), University of Sindh, Jamshoro, Pakistan

\section{Manuscript Info}

Manuscript History

Received: 04 February 2017

Final Accepted: 01 March 2017

Published: April 2017

Key words:-

360-degree feedback, performance

evaluation, organizational Growth, ratee, rater.

\begin{abstract}
360-degree feedback is modern method of employee performance evaluation. It presents a clear picture of the employee's performance and organizational environment and progress. It supports the organization for being adaptive and flexible according to the needs of their personnel. In the 360-degree feedback usually comments and views are taken from superior, peers, subordinates, worker and customers, and after the evaluation is complete the feedback is shared with the employee giving them a clear illustration and even suggesting areas for their growth by giving career developmental sessions. This paper presents the study of human resource literature and analyses the contribution of 360 feedbacks for both employee and organizational growth. The purpose is to suggest practice of 360-degree feedback in the higher educational institutes of Pakistan. Because from the study of the literature, it has been established that not only 360-degree feedback helps employees in their career development but also enhances organization performance.
\end{abstract}

Copy Right, IJAR, 2017,. All rights reserved.

\section{Introduction:-}

An organization is a group of elements in which each element works for achieving a common goal. Some of the important elements are employee, employer, customer, services and organizational behavior. All of these elements needed to be synchronized and connected. In many organizations, 360-degree feedback method is used to assess the connection among organizational elements and growth. The primary objective of this paper is to establish importance of the 360-degree feedback on employee and organizational growth and describe a model for Pakistani higher educational institutes. Limited studies are available on the usage of 360-degree feedback in Pakistan therefore another objective is to contribute in the knowledge in this notion for further research in Pakistan

\section{What is 360-degree feedback?}

360 degree feedback is generally defined as "The systematic collection and feedback of performance data on individual or group derived from a number of stakeholders in their performance"(Ward, 2003, p.4). It constitutes ratee, supervisor, peer, subordinates, customer, supplier, mentor/coach and external raters(Mount, Judge, Scullen, Sytsma, \& Hezlett, 1998).In perspective of managers 360 degree feedback (Hazucha, Hezlett, \& Schneider, 1993)"is an assessments process used to improve managerial effectiveness by providing the manager with a more complete assessment of the employee's effectiveness, his development and performance needs". Feedback is needed for the development and improvement of the rate and his learning should be integrated in order to provide better performance. Contemporary 360 degree feedback implied that organizational growth depends on the development of 
individual with systematic approach including all elements of the organization. Thus, it also refers to as multi-source feedback, multi-rater feedback, full-circle feedback and group performance review(Maurer, 2002).

\section{Process of 360-degree feedback Method:-}

Historically, 360-degree feedback was used in USA military (1940s), later on the corporate firms utilize this method for individuals (1960-1970).Through literature search the model is adapted for 360 degree feedback(Kutcher, Donovan, \& Lorenzet, 2009; Waldman, Atwater, \& Antonioni, 1998). It is an organizational process that includes: planning, meetings with the ratee, feedback tool designing, development of report, results delivery, review the feedback, learning, follow-up.(Figure a).

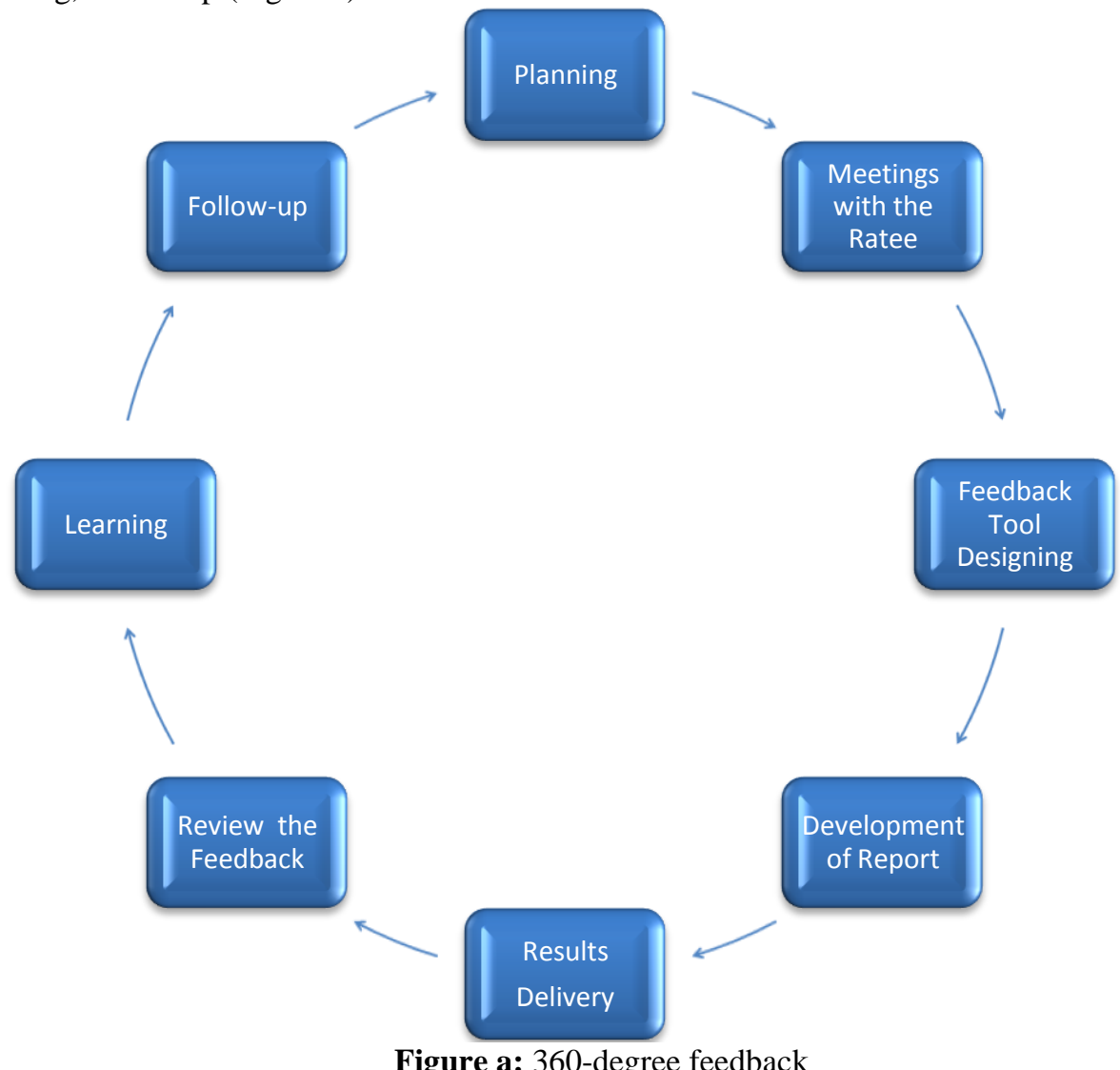

The supervisor is the main feedback collector and completes the whole feedback cycle. S/he ensures the delivering of results of the feedback to the ratee in a constructive way and re-invents the plan to overcome the deficiencies. As a rater the supervisor could provide more effective feedback with full knowledge of existing skills and competencies for the work requirements. However, the personal bias is the major disadvantage in this process.

Most of the time, the ratee could also supply valuable feedback of his/her weakness and strengths. However, it could be overly positive or could be self-demeaning(WImer, 2006). Multiple-Peer raters are more effective in prediction of the future growth especially in team-oriented task. For reducing grievances feedback reports are kept confidential.

Feedback from subordinates mostly rates on the interpersonal skills. More than two subordinates act as rater to get average rates. Customers as rater are the most valuable in their feedbacks on outputs rather than work processes internal of the organization(McCarthy \& Garavan, 2001).

\section{Reasons for adopting 360 degree feedback:-}

Today, many organizations derive to adopt 360 degree feedback to Leadership development(Manfred, 2004).Now a days 360-degree feedback has gained increased importance because of several reasons. Some of these are: organizations have found that the 360-degree feedback from employees and customers helps them overcome performance gaps which improve their growth (Mohapatra, 2015). Managers are provided with the subordinates, 
peer and customer feedback to change behavior and improve in performance(McCarthy \& Garavan, 2001). However, self-rating by the manager provide more accurate feedback regarding his own weaknesses and strengths. It is also linked to several positive outcomes like better performance, enhanced interpersonal communication, improved work relationships, etc. (Rai \& Singh, 2005). Other reasons for adopting 360 degree feedback are: assessment of training needs, team evaluation, organizational change and assistance in performance management(Craig, 2001).

\section{0-degree feedback: employee and organization growth:-}

The 360-degree feedback establishes an environment of constant learning and provides a holistic feedback to employees that lead to improved performance and increased organizational growth (Alexander, 2006). The growing utilization of 360-degree feedback for performance review in organizations is considered as the method to collect information from multiple sources. It encompasses the navigation from multi-sources for the improvement of the employee. Findings claimed that the success of 360 degree feedback depends on planned implementation. Prerequisite of implementation is a commitment from the top management, indulging of human resource department and uninterrupted provision of resources, especially time and financial(Tornow \& London, 1998). However,(Bracken, Timmreck, Fleenor, \& Summers, 2001) accentuated that definition of success depends on the individual own perspective and most importantly defined by the organization. Many studies revealed that 360 degree feedback is essential for individuals only as its conjunction with identification of personal strengths(Hensel, Meijers, van der Leeden, \& Kessels, 2010; Maurer, 2002). Based on the assumption of the Cognitive Dissonance Theory, individual improved after getting a self-rating and multi-source rating in order to reduce deficiencies and increase the feeling of being assonant(Brutus, London, \& Martineau, 1999). However, it was evident that mostly the ratings are based on interpersonal interactions rather than performance. The method is more effective when focused on behaviors and job responsibilities. This would increase by maintaining the confidentiality. Many organizations claimed and proved that the confidentiality of raters and data enhance self-esteem and showed the harmonization of work(Ghorpade, 2000). It also provides some insight into the unexplored areas of the employee personal and professional development by his supervisor or by himself. However, (Kaplan, 1993)finds that too often feedbacks from supervisors hardly change the employee's behavior. Nevertheless, feedback helps employees in self-judgment and self-improvement according to the organization's needs(McCarthy \& Garavan, 2001). It embeds positive norms and values with growth in working competencies and hence, proved to be a powerful tool for organizational change. It derives not only individual to change instead the whole organizational culture mapped towards continuous improvement. Although, direct communication and support for immediate improvement is necessary between supervisor and employee for review, the multi-source feedback promotes the constructive open communication. The studies on 360 degree feedback reveals employees' and organizations' hidden strengths, despite that few authors claimed that the method focused on weaknesses only(Bracken, et al., 2001). However, this could be overcome by the prior explanation of all the objectives of conducting the feedback and subsequently weaknesses identified and help in shaping the future development of employee and the organization. The 360 degree feedback considered as the substitute of the performance appraisals that could be redefined as the part of the performance appraisal procedure as it is a continuous process not a onetime activity(DeNisi \& Kluger, 2000). Other characteristic of 360 degree feedback depends on experience of the raters. Analysis of various studies embossed that validity of raters in rating demonstrates better outcomes that helps in decision making and growth. Developmental purposes of the employee and organization should be taken into account when designing the feedback tool. The objectives of the 360 degree feedback could be blurred if linked with the financial incentives and it could diverge it towards performance appraisal. Thus, it helps in building the leadership and management qualities in the employee and contributing towards organizational growth(London \& Beatty, 1993).Therefore, organizational culture and behavior become more adaptive to administering the 360 degree feedback regularly.

360 degree feedback: with reference to Higher Education Institutes of Pakistan:-

Higher education institutes constitute the major part in producing the work force that contributes in the economical development of the country, therefore, both teaching and implementing this method is effective for the growth of employees and institutes. It will also create a future workforce equipped on this method for performance review. In Pakistan, public sector organizations adopt 360 degree feedback as part of their performance appraisals, training and development of the employees, team building and strategic development (Hameed \& Waheed, 2011). They also emphasized on the preplanned bases and criteria's for feedback. However, in the public sector the 360 feedback is mostly used for appraisals for salary increments(Saqib, Khan, Ahmed, \& Ullah, 2012). Although, there is long term impact of 360 degree feedback and it is also observed by many authors that 360 degree feedback enhances the leadership development (Abbas \& Yaqoob, 2009; Day, 2001). The effectiveness of this method is proven in 
increasing motivation of the employees and bridging the communication gap between the manager and coworkers(Ward, 2003, p.4).

It also established that better attitudes, reduction in stress and anxiety of the employees are achieved through the self-assessment and multi-rater processes used in the 360 degree feedback (Ahmed, Hussain, Ahmed, \& Akbar, 2010; Rycroft- Malone et al., 2004).The degree awarding higher education institutes particularly medical institutes adopt the 360 degree feedback for accreditation (Archer, 2010).Public sector universities incorporate 360 degree feedback for teachers as the method of performance appraisals (Anjum, Yasmeen, \& Khan, 2011; Rasheed, Yousaf, \& Noor, 2011). Higher education institutes involved various stakeholders, management, teachers, office staff, students and their parents. Feedback from all stakeholders as the raters provides significant improvisation of the institutes.

However, there are various hindrances that accounts for implication of 360-degree mechanism in higher education institutes. Most of them are untrained raters, personal biases and absence of planned feedback mechanism(Anjum, et al., 2011; Archer, 2010; Chaudhry \& Ramay, 2011). Nevertheless, preplanned mechanism provides quality of the feedback data (Van Vught \& Westerheijden, 1994) and subsequently increase the quality of the higher education institutes(Ali, 2009; Anjum, et al., 2011; Rasheed, et al., 2011). At all levels of workforce hierarchy and organizational level implementation of 360-degree feedback mechanism has positive impact on the sustainable development and growth.

\section{Proposed Model:-}

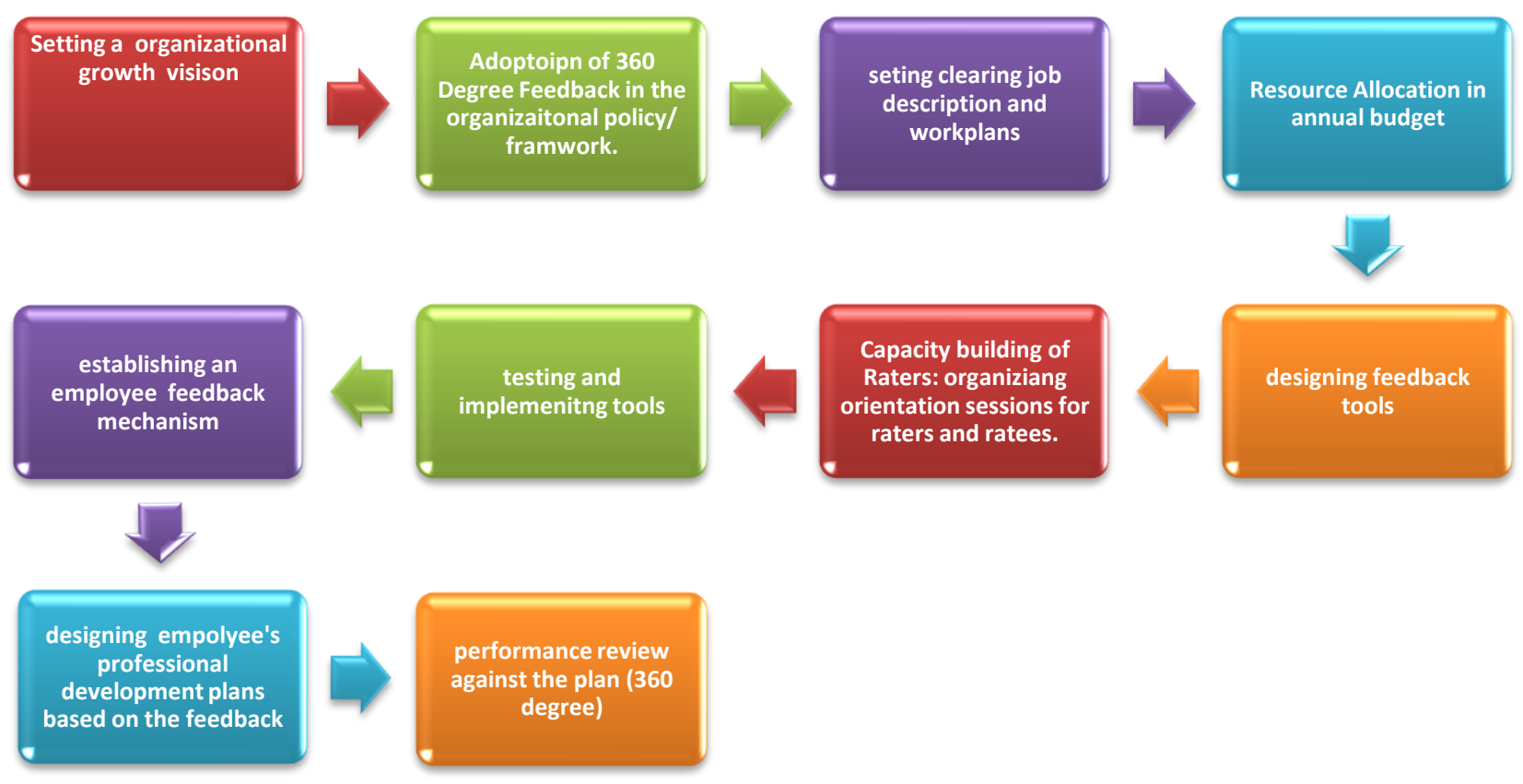

\section{Conclusion:-}

Figure b:- Model for 360 degree Feedback

Employees are assets of the organization and contribute in its growth and profits. Their development is linked with the growth of the organization. 360-degree feedback is the most comprehensive appraisal tool. 360 degree reviews are intended to give an employee the opportunity to understand and remedy any areas of improvement or issues that may exist between themselves and the rest of the organization (Alexander, 2006). This process provides an insight on the employees' performance, behaviors and progress as well as their potential, while, recognizing and establishing performance development goals. However, the impact of 360 degree feedback on employee and organization growth depends on the planned implementation and organizational policies. The 360 degree feedback is used in some organizations in Pakistan as well but studies on its usages in higher education institutes are limited. However, it would be beneficial for the higher education institutes as a tool for organizational growth and for 
capacity building of the future workforce. Therefore, its application facilitates in sustainable development of employee and organization.

\section{References:-}

1. Abbas, Q., \& Yaqoob, S. (2009). Effect of leadership development on employee performance in Pakistan. Pakistan Economic and Social Review, 269-292.

2. Ahmed, A., Hussain, I., Ahmed, S., \& Akbar, M. F. (2010). Performance appraisals impact on attitudinal outcomes and organisational performance. International Journal of Business and Management, 5(10), 62.

3. Alexander, M. D. (2006). HOW DO 360 DEGREE PERFORMANCE REVIEWS AFFECT EMPLOYEE. Rhode Island: University of Rhode Island.

4. Ali, A. (2009). The Role of Leadership in Human Resource Management a Comparative Study of Specific Public and Private Sectors in Pakistan. Journal of Management and Social Sciences, 5(2), 180-194.

5. Anjum, A., Yasmeen, K., \& Khan, B. (2011). Performance appraisal systems in public sector Universities of Pakistan. International journal of human resource studies, 1(1), 41.

6. Archer, J. C. (2010). State of the science in health professional education: effective feedback. Medical education, 44(1), 101-108.

7. Bracken, D. W., Timmreck, C. W., Fleenor, J. W., \& Summers, L. (2001). 360 feedback from another angle. Human Resource Management, 40(1), 3-20.

8. Brutus, S., London, M., \& Martineau, J. (1999). The impact of 360-degree feedback on planning for career development. Journal of Management Development, 18(8), 676-693.

9. Chaudhry, S., \& Ramay, M. I. (2011). ISO 9001 (a Standard) to Develop a Robust Governance System in Higher Education Institutions. A case study of a degree awarding Institute in Pakistan. Interdisciplinary Journal Of Contemporary Research In Business, 3(2), 1456.

10. Craig, T. C. (2001). Hand Book of Leadership Development (p.32)

11. Day, D. V. (2001). Leadership development:: A review in context. The Leadership Quarterly, 11(4), 581-613.

12. DeNisi, A. S., \& Kluger, A. N. (2000). Feedback effectiveness: can 360-degree appraisals be improved? The Academy of Management Executive, 14(1), 129-139.

13. Ghorpade, J. (2000). Managing five paradoxes of 360-degree feedback. The Academy of Management Executive, 14(1), 140-150.

14. Hameed, A., \& Waheed, A. (2011). Employee development and its affect on employee performance a conceptual framework. International journal of business and social science, 2(13).

15. Hazucha, J. F., Hezlett, S. A., \& Schneider, R. J. (1993). The impact of 360-degree feedback on management skills development. Human Resource Management, 32(2-3), 325-351.

16. Hensel, R., Meijers, F., van der Leeden, R., \& Kessels, J. (2010). 360 degree feedback: how many raters are needed for reliable ratings on the capacity to develop competences, with personal qualities as developmental goals? The International Journal of Human Resource Management, 21(15), 2813-2830.

17. Kaplan, R. E. (1993). 360-degree feedback PLUS: Boosting the power of co-worker ratings for executives. Human Resource Management, 32(2-3), 299-314.

18. Kutcher, E., Donovan, J., \& Lorenzet, S. J. (2009). 360-Degree Feedback. Handbook of Improving Performance in the Workplace: Volumes 1-3, 221-250.

19. London, M., \& Beatty, R. W. (1993). 360-degree feedback as a competitive advantage. Human Resource Management, 32(2-3), 353-372.

20. Manfred, F. R. K. d. V., Pierre Vrignaud and Elizabeth Florent-Treacy. (2004). The Global Leadership Life Inventory:development and psychometric properties of a 360-degree feedback instrument. The International Journal of Human Resource Management ,ISSN 0958-5192 print/ISSN 1466-4399 online q 2004 Taylor \& Francis Ltd Retrieved From: http://www.tandf.co.uk/journals

21. Maurer, T. J., Debora R. D. Mitchel andFrancisco G. Barbeite. (2002). Predictors of attitudes toward a 360degree feedback system and involvement in post-feedback management development activity. Journal of occupational and Organizational Psychology, 75, 87-107.

22. Mohapatra, M. (2015). 360 Degree Feedback: A Review of Literature. International Journal of Research and Scientific Innovation, 112-116.

23. McCarthy, A. M., \& Garavan, T. N. (2001). 360 feedback process: Performance, improvement and employee career development. Journal of European Industrial Training, 25(1), 5-32.

24. Mount, M. K., Judge, T. A., Scullen, S. E., Sytsma, M. R., \& Hezlett, S. A. (1998). Trait, rater and level effects in 360degree performance ratings. Personnel Psychology, 51(3), 557-576. 
25. Rai, H., \& Singh, M. (2005). Mediating Effects in the Relationship between 360 Degree Feedback and Employee Performance. Ahmedabad: Indian Institute of Management .

26. Rasheed, M. I., Yousaf, H. D. A. S., \& Noor, A. (2011). A critical analysis of performance appraisal system for teachers in public sector universities of Pakistan: A case study of the Islamia University of Bahawalpur (IUB). African Journal of Business Management, 5(9), 3735.

27. Rycroft-Malone, J., Seers, K., Titchen, A., Harvey, G., Kitson, A., \& McCormack, B. (2004). What counts as evidence in evidence-based practice? Journal of advanced nursing, 47(1), 81-90.

28. Saqib, M., Khan, M. A., Ahmed, M., \& Ullah, I. (2012). A Brief Review of Performance Appraisal Practices and its Implementation at Government Offices in Pakistan. Interdisciplinary Journal Of Contemporary Research In Business, 3(10), 1057.

29. Tornow, W. W., \& London, M. (1998). Maximizing the Value of 360-Degree Feedback: A Process for Successful Individual and Organizational Development: ERIC.

30. Van Vught, F. A., \& Westerheijden, D. F. (1994). Towards a general model of quality assessment in higher education. Higher Education, 28(3), 355-371.

31. Waldman, D. A., Atwater, L. E., \& Antonioni, D. (1998). Has 360 degree feedback gone amok? The Academy of Management Executive, 12(2), 86-94.

32. Ward, P. (2003, p.4). Developing Practice:360 degree feedback

33. WImer, B. S. W. K. M. N. (2006). 13 Common Mistakes Using 360-Degree Feedback:Here's how to avoid some common mis-steps when implementing multirater feedback. 